\title{
Effects of Retinoids on Vasculatures
}

\author{
Rehana Parvin, Akiko Saito-Hakoda, Susumu Suzuki, Erika Noro, Hiroki Shimada, Atsushi Yokoyama and Akira \\ Sugawara*
}

Department of Molecular Endocrinology, Tohoku University Graduate School of Medicine, Japan

Submission: June 20, 2017; Published: July 06, 2017

*Corresponding author: Akira Sugawara, Professor, Department of Molecular Endocrinology, Tohoku University Graduate School of Medicine, 2-1, Seiryo-machi, Aoba-ku, Sendai, Miyagi, 980-8575, Japan,Tel: 022-717-7483; Fax: 022-717-8083; Email: akiras2i@med.tohoku.ac.jp

\begin{abstract}
Retinoids are natural and synthetic derivatives of retinol, otherwise known as vitamin A. Retinoids bind to several classes of proteins including retinoid-binding proteins and retinoid nuclear receptors leading to the activation of specific regulatory elements of DNA that are involved in regulating cell growth, differentiation, and apoptosis. Several clinical studies have examined the role of retinoids in disease, and research is still ongoing. A natural retinoid, all-transretinoic acid, possesses various beneficial effects on the vasculature. ATRA regulates various types of important cellular functions via retinoic acid receptor. Thromboxane induced contraction and proliferation of vascular smooth muscle cells was completely abrogated by retinoid treatment,which has been recognized to have beneficial effects against atherosclerotic vascular disorders. Therefore retinoids can be a potential therapeutic candidate against vascular disorders. At present, retinoids are used in various fields of medicine. This paper aims to review the recently revealed actions of retinoids on the vasculature as well as some of their current use in vasculogenesis.

Keywords: Retinoids; Vasculatures

Abbreviations: RA: Retinoic Acid; RAR: Retinoic Acid Receptor; RXR: Retinoid X Receptor; ATRA: All-Trans Retinoic Acid; Ppars: Peroxisome Proliferator-Activated Receptors; VDR: Vitamin D Receptor; THR: Thyroid Hormone Receptors; FXR: Farnesoid X Receptor; LXR: Liver X Receptor VSMC: Vascular Smooth Muscle Cell; EC: Endothelial Cell; AKAP: A-Kinase Anchoring Protein; TX: Thromboxane; TXR: Thromboxanereceptor; Enos: Endothelial NO Synthase; NO: Nitric Oxide; KLF5: Kruppel-Like Zinc-Finger Transcription Factor 5; KLF4: Kruppel-Like Zinc-Finger Transcription Factor 4; CAD: Coronary Artery Disease; IR: Ischemia/Reperfusion; BBB: Blood Brain Barrier; MCAO: Middle Cerebral Artery Occlusion
\end{abstract}

\section{Introduction}

Retinoids are natural active metabolites and synthetic derivatives of vitamin A (retinol) [1]. Though vitamin A was discovered more than one hundred years ago, the research history of vitamin A began in 1925 when rats deprived of dietary vitamin A showed increased epithelial growth, including neoplastic responses [2]. Vitamin A is an essential vitamin a deficiency of which causes impaired cellular differentiation, reduced resistance to infection, anemia and even death. In contrast, many aquatic species like sharks may be protected from cancer as a result of their high vitamin A content [3]. At present, retinoids are used in dermatological diseases [4], as a primary treatment for acute promyelocytic leukemia [5] and also for Cushing's disease [6].

\section{Retinoids}

Almost three decades ago, nuclear retinoic acid receptors were identified that belong to the superfamily of nuclear receptors, which led to significant progress in understanding the mechanism of action of retinoids. Retinoids show their biological effects through specific members of the steroid hormone nuclear receptor family, including retinoic acid receptor (RAR) and retinoic X receptor (RXR). RAR and RXR possess three subtypes, $\alpha, \beta$, and $\gamma$ with various isoforms. Active metabolites of retinol, retinoic acid (RA) have different forms, including all-trans RA (ATRA), 9 cis RA, all-trans 3-4 didehydro RA, and 4-oxo RA, whose synthesis is probably cell specifically modulated [7-10]. RARs $\alpha, \beta$ and $\gamma$ bind both ATRA and 9-cis RA with high affinity, while RXR $\alpha, \beta$ and $\gamma$ only bind rapaciously to 9-cis RA, and 13-cis-RA activates neither RAR nor RXR. The physiological function of 13-cis RA is detected at very lower concentrations in both mice and humans $[11,12]$. The retinoid,13-cis RA is not a ligand for retinoid receptors, but can be readily converted to one. Moreover, 13-cis-RA and ATRA occur in vivo, whereas the in vivo occurrence of 9-cis-RA remains controversial $[12,13]$. $\mathrm{RAR} \alpha, \mathrm{RXR} \alpha$, and $\operatorname{RXR} \beta$ are ubiquitously expressed, whereas $\operatorname{RAR} \beta, \gamma$, and $\operatorname{RXR} \gamma$ are expressed in tissue-restricted patterns 
[14-16]. RXRs regulate transcription as either a homodimer or as an obligatory heterodimeric partner for various other subclass I nuclear receptors, including RARs, peroxisome proliferatoractivated receptors (PPARs), the vitamin D receptor (VDR), thyroid hormone receptors (THR), the farnesoid $X$ receptor (FXR), and the liver $\mathrm{X}$ receptor (LXR). In the absence of a ligand, RXR forms homo-tetramers that are transcriptionally inactive but rapidly dissociate into active dimers upon ligand binding [17-19]. RA mediates its biological functions through binding to and activating ligand-activated transcription factors that regulate gene expression $[17,18]$. Thus, RARs and RXRs help maintain homeostasis and function as metabolite sensors either directly, through their own action, or as a necessary partner for the other key transcriptional regulators $[20,21]$.

\section{Retinoids and Vasculature}

Retinoids possess pleiotropic agents of therapy for vascular diseases, dermatological and neoplastic diseases. Since vascular smooth muscle cells (VSMCs) and endothelial cells (ECs) express most retinoid receptors, the mechanisms underlying retinoidmediated events in these cells and the vessel wall are related to altered genetic variations. Therefore, retinoid-response genes represent promising therapy targets for the treatment of vascular diseases [22]. In this review, we will consider the recent advances in the understanding of retinoids and their relationship with the vasculature. Retinoids are versatile biological response modifiers of the vascular smooth muscle phenotype [23]. Other research has demonstrated a novel function for retinoids in the induction of an A-kinase anchoring protein (AKAP) tumor suppressor that blocks VSMC growth providing novel molecular observations concerning how retiniods may utilize their anti-proliferative effects in the injured vessel wall [24]. ATRA has been reported to be beneficial for atherosclerotic vascular disorders by inducing differentiation and inhibiting the proliferation of VSMCs $[23,25,26]$. Moreover, retinal pigment epithelium rescues the vascular endothelium from retinoic acid-induced apoptosis [24]. RA and nuclear receptor, RAR-mediated signalling have protective effects on the vascular system. Whether the circulating levels of RA are associated with mortality in patients with coronary artery disease is still not known [27]. Our previous research showed that thromboxane (TX) A2 induces contraction and proliferation of VSMCs through its specific membrane TX receptor (TXR), probably leading to the progression of atherosclerosis. TXR gene expression and transcriptional activity were diminished by ATRA or 9-cis retinoic acid. TX induced contraction and proliferation of VSMCs were completely abrogated by ATRA treatment, which has been recognized to have a beneficial effect against atherosclerotic vascular disorders. Our study revealed a novel anti-atherosclerotic action of retinoids in VSMCs [28].

ATRA increases the antithrombotic effect in microvascular EC, a very relevant compartment for tumor and/or antitumor therapy-associated vascular complications [29].
Retinoid-regulated cellular responses, such as cell growth and differentiation, are also central to vascular injury and atherosclerosis. There are many fundamental issues regarding the effects of retinoid, and retinoid receptors play a role in atherosclerosis and cardiovascular disease in general. ATRA can play an important role in the early steps of lymphatic vasculature development [30]. The RA metabolic pathway is activated in CAD patients with different levels of heart functionality and human atherosclerotic plaques. Moreover, the effects of ATRA on the expression of RA target genes and the proliferation of endothelial cells, smooth muscle cells, cardiofibroblasts, and cardiomyocytes were examined. ATRA may be used to delay remodelling, decrease restenosis, and preserve the functions of the cardiovascular system [31].

ATRA has been reported to promote differentiation and inhibit proliferation, cell migration, inflammation, and extracellular matrix synthesis of VSMCs as well as repress neointima formation and restenosis after balloon injury $[23,32]$. ATRA has also been reported to attenuate ventricular remodelling after myocardial infarction [33]. In addition, we have recently shown that ATRA stimulates nitric oxide (NO) production by endothelial NO synthase (eNOS) phosphorylation through RAR-mediated activation in vascular ECs [34]. NO is a potent vasodilator and signal modulator molecule that plays important roles in controlling vascular function. Therefore, ATRA may be a novel therapeutic candidate for vascular disorders with endothelial damage. ATRA ameliorated high fat diet-induced atherosclerosis in rabbits by inhibiting platelet activation and inflammation [35]. Additionally, RAR $\alpha / \beta$ agonist Am80 has been reported to prevent in-stent neointima formation [36], suppress macrophage foam cell formation, prevent atherogenesis [37], and ameliorates murine vasculitis [38]. The RA signalling pathway is activated in post-ischemic hearts and may play a role in regulating damage and repair during remodelling [39]. Am80 repressed the transcriptional activity of Kruppel-like zinc-finger transcription factor 5 (KLF5), which seems to be a key element linking external stress and cardiovascular remodelling $[40,41]$. Am80 also affected the function of KLF5 via RAR and then induced the expression of the growth arrest gene p21, inhibiting the proliferation of the smooth muscular cells [42]. Kruppel-like zinc-finger transcription factor 4 (KLF4) is required for VSMC differentiation and is augmented by ATRA [43].

The new RXR agonist HX630 exerts antiproliferative effects in VSMCs in vivo and in vitro suppressing intimal hyperplasia. Thus, the RXR may serve as a therapeutic target for vascular injury and intimal thickening [44]. The altered gene expression profile of CD34+ cells in coronary artery disease (CAD) patients was related to activation and differentiation by a RA-induced differentiation program leading to a reduced capacity to migrate to ischemic tissues in CAD patients [45]. In this review, ATRA was also reported to be beneficial for atherosclerotic vascular disorders 
by inducing differentiation and inhibiting the proliferation of VSMCs, which is recently receiving more attention in researchon cardiovascular disorders [23,25,28,30,33,34,39,37].

ATRA attenuates hepatic ischemia/reperfusion (IR) injury in rats [46]. Moreover, RAR $\alpha$ mediated ATRA pre-treatment alleviated liver IR injury by inducing autophagy [47]. RA and environmental enrichment alter the sub-ventricular zone and striatal neurogenesis after stroke [48]. RA participates in blood brain barrier (BBB) development, preventing the disruption of BBB in ischemic stroke. Therefore, RA could be a good treatment for alleviating the ischemic stroke-induced increase of vascular permeability, as suggested in rat models of middle cerebral artery occlusion (MCAO) [49]. Moreover, RA-loaded polymeric nanoparticles improve the vascular regulation of neural stem cell survival and differentiation after ischemia [50]. From the above discussion, it can be concluded that retinoids could be a promising candidate for the treatment of vasculature-related diseases of the heart, liver, and brain.

\section{Conclusion}

Almost one century has passed since retinoid research was first reported. Reports describing novel pleotropic effects are still being published. In our previous research, we showed that ATRA increases NO production by eNOS phosphorylation through RAR $\alpha$ mediated activation in vascular ECs and probably has beneficial effects in the vascular endothelium. Therefore, retinoids may be novel therapeutic agents against vascularrelated disorders with endothelial damage. In this review, we considered recent advances in research on retinoids and their relationship with atherosclerosis and vascular disorders.Very recently we demonstrated the inhibitory effect of HX630 on Pomc gene regulation via RXR [6]. In the future, it could be useful to examine the RXR-mediated effect of HX630 on vasculaturerelated genes in VSMC and EC, which may lead to the discovery of new treatments for various types of vascular disease. Additional studies are needed to elucidate how metabolite-specific retinoid effects affect the vasculature in various organs including the heart, brain and liver.

\section{Acknowledgement}

This work was supported by Japan Society for the Promotion of Science (JSPS) KAKENHI Grant Number $16 \mathrm{H} 03252$ (for AS), 16K15492(for AS), and 15K09420 (for ASH).

\section{Conflict of Interest}

The authors have declared that no competing interests exist.

\section{References}

1. Sporn MB, Dunlop NM, Newton DL, Smith JM (1976) Prevention of chemical carcinogenesis by vitamin A and its synthetic analogs (retinoids). Fed Proc 35(6): 1332-1338.

2. Wolbach SB, Howe PR (1925) Tissue Changes Following Deprivation of Fat-Soluble a Vitamin. J Exp Med 42(6): 753-777.
3. Prieur DJ, Fenstermacher JD, Guarino AM (1976) A choroid plexus papilloma in an elasmobranch (Squalus acanthias). J Natl Cancer Inst 56(6): 1207-1209.

4. Fritsch P (1983) Use of systemic retinoids in dermatology. Wien Klin Wochenschr 95(23): 817-822.

5. Ferrara F (2010) Acute promyelocytic leukemia: what are the treatment options? Expert Opin Pharmacother 11(4): 587-596.

6. Saito-Hakoda A, Uruno A, Yokoyama A, Shimizu K, Parvin R, et al. (2015) Effects of RXR Agonists on Cell Proliferation/Apoptosis and ACTH Secretion/Pomc Expression. PLoS One 10(12): e0141960.

7. De Luca LM (1991) Retinoids and their receptors in differentiation, embryogenesis, and neoplasia. FASEB J 5(14): 2924-2933.

8. Keaveny M, Stunnenburg HG (1995) Retinoic acid receptors. In Indicible Gene Expression pp. 187-242.

9. Leid M, Kastner P, Chambon P (1992) Multiplicity generates diversity in the retinoic acid signalling pathways. Trends Biochem Sci 17(10): 427-433.

10. Napoli JL (1996) Regulation of the biosynthesis and catabolism of retinoids. FASEB J 10(9): 993-1001.

11. Kane MA, Chen N, Sparks S, Napoli JL (2005) Quantification of endogenous retinoic acid in limited biological samples by LC/MS/MS. Biochem J 388(Pt 1): 363-369.

12. Tang GW, Russell RM (1990) 13-cis-retinoic acid is an endogenous compound in human serum. J Lipid Res 31(12): 175-182.

13. Napoli JL, Pramanik BC, Williams JB, Dawson MI, Hobbs PD (1985) Quantification of retinoic acid by gas-liquid chromatography-mass spectrometry: total versus all-trans-retinoic acid in human plasma. J Lipid Res 26(3): 387-392.

14. Dolle P, Ruberte E, Leroy P, Morriss-Kay G, Chambon P (1990) Retinoic acid receptors and cellular retinoid binding proteins. I. A systematic study of their differential pattern of transcription during mouse organogenesis. Development 110(4): 1133-1151.

15. Mangelsdorf DJ, Borgmeyer U, Heyman RA, Zhou JY, Ong ES, et al. (1992) Characterization of three RXR genes that mediate the action of 9-cis retinoic acid. Genes Dev 6(3): 329-344.

16. Dolle P, Fraulob V, Kastner P, Chambon P (1994) Developmental expression of murine retinoid X receptor (RXR) genes. Mech Dev 45(2): 91-104.

17. Kersten S, Reczek PR, Noy N (1997) The tetramerization region of the retinoid $\mathrm{X}$ receptor is important for transcriptional activation by the receptor. J Biol Chem 272(47): 29759-29768.

18. Kersten S, Dong D, Lee W, Reczek PR, Noy N (1998) Auto-silencing by the retinoid X receptor. J Mol Biol 284(1): 21-32.

19. Gampe RT, Montana VG, Lambert MH, Wisely GB, Milburn MV, et al. (2000) Structural basis for autorepression of retinoid $X$ receptor by tetramer formation and the AF-2 helix. Genes Dev 14(17): 2229-2241.

20. Yu VC, Delsert C, Andersen B, Holloway JM, Devary OV, et al. (1991) RXR beta: a coregulator that enhances binding of retinoic acid, thyroid hormone, and vitamin D receptors to their cognate response elements. Cell 67(6): 1251-1266.

21. Kliewer SA, Umesono K, Mangelsdorf DJ, Evans RM (1992) Retinoid $\mathrm{X}$ receptor interacts with nuclear receptors in retinoic acid, thyroid hormone and vitamin D3 signalling. Nature 355(6359): 446-449.

22. Streb JW, Miano JM (2003) Retinoids: pleiotropic agents of therapy for vascular diseases? Curr Drug Targets Cardiovasc Haematol Disord 3(1): 31-57. 
23. Miano JM, Berk BC (2000) Retinoids: versatile biological response modifiers of vascular smooth muscle phenotype. Circ Res 87(5): 355362.

24. Streb JW, Long X, Lee TH, Sun Q, Kitchen CM, et al. (2011) Retinoidinduced expression and activity of an immediate early tumor suppressor gene in vascular smooth muscle cells. PLoS One 6(4): e18538.

25. Miano JM, Berk BC (2001) Retinoids: new insight into smooth muscle cell growth inhibition. Arterioscler Thromb Vasc Biol 21: 724-726.

26. Kagechika H, Shudo K (2005) Synthetic retinoids: recent developments concerning structure and clinical utility. J Med Chem 48(19): 58755883.

27. Liu Y, Chen H, Mu D, Li D, Zhong Y, et al. (2016) Association of Serum Retinoic Acid with Risk of Mortality in Patients With Coronary Artery Disease. Circ Res 119(4): 557-563.

28. Uruno A, Sugawara A, Kudo M, Sato M, Sato K, et al. (2003) Transcription suppression of thromboxane receptor gene expression by retinoids in vascular smooth muscle cells. Hypertens Res 26(10): 815-821.

29. Marchetti M, Vignoli A, Bani MR, Balducci D, Barbui T, et al. (2003) Alltrans retinoic acid modulates microvascular endothelial cell hemostatic properties. Haematologica 88(8): 895-905

30. Marino D, Dabouras V, Brandli AW, Detmar M (2011) A role for all-transretinoic acid in the early steps of lymphatic vasculature development. J Vasc Res 48(3): 236-251.

31. Bilbija D, Elmabsout AA, Sagave J, Haugen F, Bastani N, et al. (2014) Expression of retinoic acid target genes in coronary artery disease. Int J Mol Med 33(3): 677-686.

32. Johst U, Betsch A, Wiskirchen J, Schober W, Vonthein R, et al. (2003) All-trans and 9-cis retinoid acids inhibit proliferation, migration, and synthesis of extracellular matrix of human vascular smooth muscle cells by inducing differentiation in vitro. J Cardiovasc Pharmacol 41(4) 526-535.

33. Paiva SA, Matsubara LS, Matsubara BB, Minicucci MF, Azevedo PS, et al. (2005) Retinoic acid supplementation attenuates ventricular remodeling after myocardial infarction in rats. J Nutr 135(10): 23262328.

34. Uruno A, Sugawara A, Kanatsuka H, Kagechika H, Saito A, et al. (2005) Upregulation of nitric oxide production in vascular endothelial cells by all-trans retinoic acid through the phosphoinositide 3-kinase/Akt pathway. Circulation 112(5): 727-736.

35. Zhou B, Pan Y, Hu Z, Wang X, Han J, et al. (2012) All-trans-retinoic acid ameliorated high fat diet-induced atherosclerosis in rabbits by inhibiting platelet activation and inflammation. J Biomed Biotechnol 2012: 259693.

36. Fujiu K, Manabe I, Ishihara A, Oishi Y, Iwata H, et al. (2005) Synthetic retinoid Am80 suppresses smooth muscle phenotypic modulation and in-stent neointima formation by inhibiting KLF5. Circ Res 97(11): 1132-1141.

37. Takeda N, Manabe I, Shindo T, Iwata H, Iimuro S, et al. (2006) Synthetic retinoid Am80 reduces scavenger receptor expression and atherosclerosis in mice by inhibiting IL-6. Arterioscler Thromb Vasc Biol 26(5): 1177-1183.
38. Miyabe C, Miyabe Y, Miura NN, Takahashi K, Terashima Y, et al. (2013) Am80, a retinoic acid receptor agonist, ameliorates murine vasculitis through the suppression of neutrophil migration and activation. Arthritis Rheum 65(2): 503-512.

39. Bilbija D, Haugen F, Sagave J, Baysa A, Bastani N, et al. (2012) Retinoic acid signalling is activated in the postischemic heart and may influence remodelling. PLoS One 7(9): e44740.

40. Shindo T, Manabe I, Fukushima Y, Tobe K, Aizawa K, et al. (2002) Kruppel-like zinc-finger transcription factor KLF5/BTEB2 is a target for angiotensin II signaling and an essential regulator of cardiovascular remodeling. Nat Med 8(8): 856-863.

41. Li D, Ma S, Yang Y, Yang D, Li G, et al. (2011) BTEB2 knockdown suppresses neointimal hyperplasia in a rat artery balloon injury model. Mol Med Rep 4(3): 413-417.

42. Zheng B, Han M, Shu YN, Li YJ, Miao SB, et al. (2011) HDAC2 phosphorylation-dependent Klf5 deacetylation and RARalpha acetylation induced by RAR agonist switch the transcription regulatory programs of p21 in VSMCs. Cell Res 21(10): 1487-1508.

43. Wang C, Han M,Zhao XM, Wen JK (2008) Kruppel-like factor 4 is required for the expression of vascular smooth muscle cell differentiation marker genes induced by all-trans retinoic acid. J Biochem 144(3): 313-321.

44. Haraguchi G, Suzuki J, Kosuge H, Ogawa M, Koga N, et al. (2006) A new RXR agonist, HX630, suppresses intimal hyperplasia in a mouse blood flow cessation model. J Mol Cell Cardiol 41(5): 885-892.

45. van der Pouw Kraan TC, Schirmer SH, Fledderus JO, Moerland PD, Baggen JM, et al. (2010) Expression of a retinoic acid signature in circulating CD34 cells from coronary artery disease patients. BMC Genomics 11: 388.

46. Rao J, Zhang C, Wang P, Lu L, Zhang F (2010) All-trans retinoic acid alleviates hepatic ischemia/reperfusion injury by enhancing manganese superoxide dismutase in rats. Biol Pharm Bull 33(5): 869875 .

47. Zhong C, Pu LY, Fang MM, Gu Z, Rao JH, et al. (2015) Retinoic acid receptor alpha promotes autophagy to alleviate liver ischemia and reperfusion injury. World J Gastroenterol 21(43): 12381-12391.

48. Plane JM, Whitney JT, Schallert T, Parent JM (2008) Retinoic acid and environmental enrichment alter subventricular zone and striatal neurogenesis after stroke. Exp Neurol 214(1): 125-134.

49. Kong L, Wang Y, Wang XJ, Wang XT, Zhao Y, et al. (2015) Retinoic acid ameliorates blood-brain barrier disruption following ischemic stroke in rats. Pharmacol Res 99: 125-136.

50. Ferreira R, Fonseca MC, Santos T, Sargento-Freitas J, Tjeng R, et al. (2016) Retinoic acid-loaded polymeric nanoparticles enhance vascular regulation of neural stem cell survival and differentiation after ischaemia. Nanoscale 8(15): 8126-8137. 
This work is licensed under Creative Commons Attribution 4.0 Licens

DOI: 10.19080/JETR.2017.02.555587
Your next submission with Juniper Publishers will reach you the below assets

- Quality Editorial service

- Swift Peer Review

- Reprints availability

- E-prints Service

- Manuscript Podcast for convenient understanding

- Global attainment for your research

- Manuscript accessibility in different formats

( Pdf, E-pub, Full Text, Audio)

- Unceasing customer service

Track the below URL for one-step submission https://juniperpublishers.com/online-submission.php 